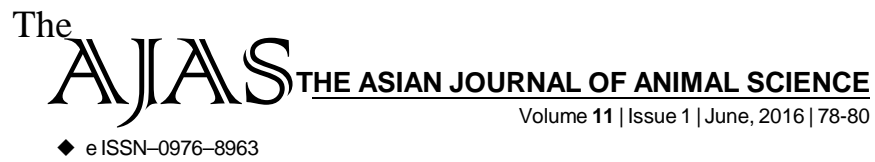

DOI : 10.15740/HAS/TAJAS/11.1/78-80

Visit us | www.researchjournal.co.in

RESEARCH NOTE

\title{
Excretory pattern and characteristics of excreta of blue rock pigeon (Columba livia)
}

\begin{abstract}
Author for Corresponding SIMRANJIT KAUR Department of Zoology, Punjab Agricultural University, LUDHIANA (PUNJAB) INDIA Email: simrankaur8734@yahoo.in
\end{abstract}

SIMRANJIT KAUR AND K.S. KHERA

See end of the article for Coopted authors'
KEY WORDS....... Excretory pattern, Excreta, Blue rock pigeon

HOW TO CITE THIS ARTICLE - Kaur, Simranjit and Khera, K.S. (2016). Excretory pattern and characteristics of excreta of blue rock pigeon (Columba livia). Asian J. Animal Sci., 11(1): -78-80 (DOI : 10.15740/HAS/TAJAS/11.1/78-80).

ARTICLE CHRONICLE - Received : 28.12.2015; Accepted : 29.05.2016
Excreta or dropping is a waste product from an animal's digestive tract expelled through the cloaca which provides information about recent meals, activities or events. Droppings age quickly. As they age, they integrate, giving rise to difficulties in the investigation of droppings. Studies regarding the chemical composition and characterization of excreta are important, as diseased condition may lead to changes in biological processes in an organism. These changes are reflected in the quantity and composition of excreta. In the present study, excreta of common bird species of agro ecosystems were collected and analysed pellet by pellet for their physical appearance, texture, colour, shape and weight (DeCant and Barrett, 2010)

The bird for our investigation was feral pigeon (Columba livia). Pigeons have thrived in our cities by adapting to life, learning to roost and breed in the seemingly inhospitable environment provided by tall buildings, and to survive on the available food. Pigeons (Columba livia) are amongst the most conspicuous urban birds, ubiquitously present in many cities worldwide (Goodwin, 1983). Pigeons are sometimes called "the flying rat" adapted to living and causing a nuisance in the cities over recent years there has been a marked increase in the numbers of feral (wild) pigeons. This bird is about $33 \mathrm{~cm}$ in length and weighs between 280 and $560 \mathrm{~g}$ with an average about $350 \mathrm{~g}$. Its plumage can vary considerably from a close resemblance to that of the original rock-dove (with blue grey plumage double black wing bars and a white rump through various "blues", "reds" and chequered types, to almost pure black. The pigeon is capable of breeding throughout the year and nests may be found in any month. However, the peak occurs between March and July. Usually, two white eggs are laid on consecutive days. Incubation lasts about 18 days with fledging taking place about 4 weeks later. A new clutch can be laid when the first young are 20 days old, therefore, upto nine broods may be produced per year by just one female pigeon (Dauwe et al., 2005).

The fecal matter and feathers of pigeon were collected from the roosting, foraging and nesting sites from three different locations of Punjab and the locations are Agronomy farm of Punjab Agricultural University, Jalandhar bypass and Mullanpur in Ludhiana and from 